\title{
ODOVTOS-Int. J. Dent. Sc. Research Impact Metrics
}

In the research and academic field, the citation analysis evaluates the impact and assumed quality of an article, a journal, an author, or an institution based on the number of times have been cited.

Recently, on June 30, 2021, our journal was notified that the 2020 Journal Citation Ranking (JCR) had been published including more journals and a new citation index, the Journal Citation Indicator $(\mathrm{JCl})$. This year the Dentistry, Oral Surgery \& Medicine list in JCR included 92 journals of Science Citation Index Expanded (SCIE), and 59 in the Emerging Sources of Citation Index (ESCl), totalizing 151 journals.

Odovtos displayed a Journal Citation Indicator of 0.07 , a Journal Normalized Citation Impact of 0.44 and a JCI Rank of 141/151, and a Q4 Quartile.

In retrospect, the data displayed in the Journal Citation Report website by Clarivate Analytics in 2015 for the journal demonstrated zero $(n=0)$ citations.

Precisely, in 2015 I was designated as Editor-in-chief of this journal. My first mission was to update past editions, build up in OJS the electronic version of the journal and modify it into a quarterly periodicity with a continuous publication system named as Online-First. As a result, we were included in ESCI in 2017, SCIELO Citation Index in 2018, and in more than 10 additional databases that allow us worldwide coverage.

Odovtos do not belong to a large company or publisher. This journal is an official scientific publication of the University of Costa Rica (UCR). The UCR is the most recognized public university of Central America and the Caribbean region and ranked 24 for Latin America, and in the range of 531-540, according to QS World University Rankings $® 2022$. Our main objective is to disseminate original and transcendental knowledge in the field of dentistry and its specialties. One of our greatest strengths is that our model implies 100\% open access articles, with no article processing charge (APC) fee. This characteristic triggered a significant increase in articles submission. Currently, our rejection rate is $62 \%$. 
Nowadays, we are encouraging the publication of articles in English, as the main language of our journal, despite being from an academic editorial in a Spanish language country, Costa Rica. Considering citation analysis of journals indexed in the SCOPUS database between the years 2018 to 2021, our journal has published 158 articles and literature reviews, adding 66 citations. In Web of Sciences through the years of 2018, 2019, 2020, we published 105 articles/reviews granting us 56 citations. These metrics mean that in the last 3 years, Odovtos impact citations have been, at least, triplicate.

The editorial board recognizes that the coverage of citation data is of paramount importance for the analyses focused on quality and impact. Thus, we are implementing a more rigorous peer-reviewing process with worldwide recognized reviewers in our field, adding more expertise and prestige, impacting the quality and coverage of the published articles. Moreover, we are implementing different bibliographic information, endorsing more prestigious databases. We included an Ethics Associate Editor and a Statistical Editor, in addition to the scientific profile (Scopus Author H-Index, Web of Science Researcher ID, and Google scholar H-index) of all members of the Editorial board. With an eye towards indicators, we will increasingly focus on recruiting high-quality reviews and research articles.

As editor-in-chief, I want to acknowledge our reviewers, researchers and readers for contributing to this success. Share your article with your network and spread your achievement!

Sincerely,

Jessie Reyes-Carmona DDS, MSD, PhD1

1. Editor-in-Chief, Odovtos International Journal of Dental Sciences, Universidad de Costa Rica.

San José, Costa Rica.

https://orcid.org/0000-0003-2872-6623

Email: jessie.reyes@ucr.ac.cr

Attribution (BY-NC) - (BY) You must give appropriate credit, provide a link to the license, and indicate if changes were made. You may do so in any reasonable manner, but not in any way that suggest the licensor endorses you or your use. (NC) You may not use the material for commercial purposes. 